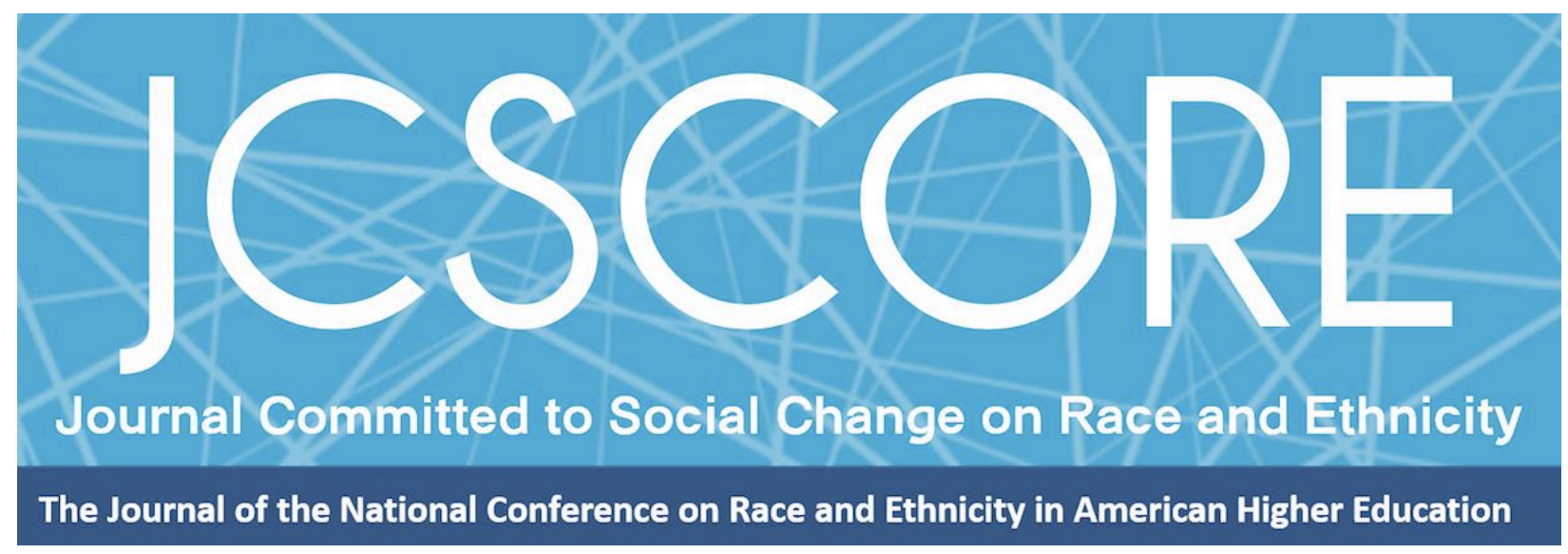

\title{
EXAMINING THE EXPERIENCES OF CAMPUS SAFETY AMONG INTERNATIONAL STUDENTS
}

\author{
Sonia H. Ramrakhiani \\ California Polytechnic State University \\ Andrew M. Byrne \\ California Polytechnic State University \\ Christopher A. Sink \\ Western Washington University
}

Journal Committed to Social Change on Race and Ethnicity

Volume 7, Issue 2 | 2021

\author{
Copyright and Open Access \\ () 2021 Sonia H. Ramrakhiani, Andrew M. Byrne, Christopher A. Sink
}

\section{(c) (i) (2) (2)}

This work is licensed under a Creative Commons Attribution-NonCommercial-ShareAlike 4.0 International License. Permission of the authors is required for distribution and for all derivative works, including compilations and translations. Quoting small sections of text is allowed as long as there is appropriate attribution and the article is used for non-commercial purposes.

The Journal Committed to Social Change on Race and Ethnicity (ISSN 2642-2387) is published by the National Conference on Race and Ethnicity (NCORE), a production of the University of Oklahoma, in partnership with the University of Oklahoma Libraries. 
Journal Committed to Social Change on Race and Ethnicity | Volume 7, Issue 2 | 2021

Examining the Experiences of Campus Safety among International Students

\author{
Sonia H. Ramrakhiani \\ California Polytechnic State University \\ Andrew M. Byrne \\ California Polytechnic State University \\ Christopher A. Sink \\ Western Washington University
}

\begin{abstract}
Although international students comprise a significant percentage of the college population, limited attention is directed to their safety needs. This study measured the experiences and perceptions of campus safety among international college students in the United States. The researchers sampled participants from institutions around the country, who self-identified as international students. A researcher-developed 53-item Likert scale questionnaire, the International College Students' Safety Questionnaire (ICSSQ), was administered to the sample. Findings from the exploratory factor analysis provided preliminary evidence for a four-factor solution for the 26-item ICSSQ with adequate internal consistency. Salient demographic variables, such as, nationality, college status and perceived proficiency in English, were found to be significantly linked to derived factor scores. Implications for institutional adoption of this instrument, along with limitations and directions for future research are included.
\end{abstract}

The United States (U.S.) is the leading host nation for international education with over a million international students for the fifth consecutive year (Institute of International Education [IIE], 2020). International college students recently contributed 44 billion dollars to the country's economy in 2019 (IIE, 2020). These students also positively contribute to the local economy, as well as to institutions' diversity of perspectives and knowledge (Lee, 2010). Despite substantial contributions by international college students, there is a dearth of research addressing their experiences and needs on American college campuses (Yao \& Viggiano, 2019). 
Journal Committed to Social Change on Race and Ethnicity | Volume 7, Issue 2 | 2021

The majority of international students in the U.S. are from non-White regions of the world. In fact, as of 2020 , only about $2 \%$ of U.S. international students originated from Canada and $1 \%$ from the United Kingdom (IIE, 2020). The majority (53\%) of international students attending U.S. universities were Chinese and Indian. Other prominent countries sponsoring students to the U.S. were South Korea, Saudi Arabia, Vietnam, Japan, Brazil, Mexico, Nigeria, Nepal and Iran (IIE, 2020). These statistics are particularly relevant as the socio-political climate in the U.S. impacts the experience and enrollment of international students. For example, "The Trump effect" (2016-2020) ushered in another round of anti-immigration (following the call for a border wall and detention of children at the border) and anti-Muslim sentiment (following the travel ban from Muslim nations) among certain sectors of the American polity (Hacker \& Bellmore, 2020). Other recent events, both on and off U.S. college campuses, have resulted in health and safety concerns for international students. Incidents of violence against people of color and the resurgence of white supremacy continue to threaten democratic institutions and the personal safety of international students. As a result of Trump era immigration restrictions and health concerns related to the current pandemic contributed to a steep enrollment decline of international students (often identifying as people of color) in American universities (Redden, 2020a; Redden, 2020b).

More specifically, Nyland et al. (2010) noted that the "fear of being stigmatized as an unsafe study destination" (p. 90) can derail efforts taken for the safety of international students. Cultural differences, adjustment and acculturation difficulties, and lack of familial and social support can compound international college students' lack of perceived safety (Marginson et al., 2010). The current study focuses on the 
Journal Committed to Social Change on Race and Ethnicity | Volume 7, Issue 2 | 2021

measurement of international college students' experiences of safety, where the international student is a student in a higher education institution who is not a citizen nor permanent resident of the U.S.

Safety, for the purposes of this research study, is defined holistically using an integrated student development theory (ISDT). Essentially, this conceptual framework attempts to synthesize the cognitive, interpersonal, psychosocial, and ecological domains (Renn \& Reason, 2013). Therefore, researchers used the following definition of campus safety for this study: a sense of feeling protected against any form of physical and/or sexual harm, as well as freedom to express oneself and develop social and emotional connections in an environment that is facilitative of academic growth.

\section{Physical and Sexual Safety}

Physical and sexual safety is widely discussed in the literature on campus safety. However, there are limited empirical studies on international students' experiences and perceptions of physical and sexual safety in the U.S., and the research that does exist presents contradictory findings (Postel, 2020; Scholl et al., 2019). According to the Association of American Universities (AAU) 2019 Campus Climate Survey on Sexual Assault and Misconduct, $13 \%$ of college students experienced non-consensual contact, with the rates being higher for women at $26.4 \%$ among undergraduate students and for transgender, genderqueer and non-binary students (TGQN) at 23.1\% (Cantor et al., 2019). Specific to the international student population, Scholl et al. (2019) examined the prevalence of physical and sexual violence among them and found that $5.5 \%$ reported sexual violence in the past year, lower than the $10.3 \%$ reported by domestic students. However, $19.6 \%$ reported physical violence, compared to the $13.5 \%$ reported by 
Journal Committed to Social Change on Race and Ethnicity | Volume 7, Issue 2 | 2021

domestic students (Cantor et al., 2019). These results suggested that international students experience higher rates of physical violence compared to sexual violence; however, international students could also be less likely to report sexual violence due to cultural factors (Postel, 2020). Furthermore, violence against female international students is far more common by known perpetrators than by strangers (Forbes-Mewett \& McCulloch, 2016).

Earlier, Bekmuratova (2012) examined the definition and perceptions of domestic violence against women among international students. The results suggested that participants differed in appropriateness of hitting and in perceptions of domestic violence based on their country of origin as well as gender. In a survey of university officials to gather information on domestic violence among international students/scholars and their spouses on U.S. campuses, Urias (2005) found that $80 \%$ of the participants reported uncertainty as to the specific number of domestic violence incidents. Forty percent of the respondents did not assume responsibility to act on behalf of their international population, but rather referred any situation to the campus police or counseling center.

Following numerous incidents of violence against Indian international students in Australia, Victoria University's Institute for Community, Ethnicity and Policy Alternatives (ICEPA) conducted a large-scale study of international students' experiences of community safety (Babacan et al., 2010). Results revealed that more than half of the international students surveyed found Australia to be less safe than they had expected. Of those who reported threats to safety, $50 \%$ of them believed these threats had a racial, religious, or cultural dimension. International students reported experiencing 
Journal Committed to Social Change on Race and Ethnicity | Volume 7, Issue 2 | 2021

verbal abuse $(58 \%)$, physical attacks $(11 \%)$, and robbery $(10 \%)$ at a much higher rate than domestic students. Furthermore, there was an evident discrepancy between the views of stakeholders and international students on the sense of community safety of international students. Many of the stakeholders believed that most violent acts against international students were "opportunistic rather than racial" in nature (Babacan et al., 2010, p. 3). While there were several limitations to the Babacan et al. (2010) study, such as sampling and low response rate, the findings brought further attention to the safety needs and well-being concerns of international students. These findings are crucial as such large-scale research with international students is absent from the U.S. safety literature despite the rise in anti-immigration sentiment during the Trump administration (Hacker \& Bellmore, 2020). Few investigations have gathered data on the experiences of international students who may often identify as Black, Brown, or Asian and feel at-risk given the rise in violence against people of color. Additionally, campus safety research tends to focus on undergraduate students, regularly overlooking the experiences of international and domestic graduate students.

\section{Social and Emotional Risk Factors}

Research evidence indicates that social and emotional adjustment in the host country can influence international students' sense of safety and student success (Baba \& Hosoda, 2014; McLachlan \& Justice, 2009; Patron, 2014; Terrazas-Carrillo et al., 2014; Zhang \& Goodson, 2011). For instance, Baba and Hosoda (2014) surveyed 209 international students from a large state university in the Silicon Valley, finding that social support was directly related to cross-cultural adjustment and served as a partial mediator for stress factors (i.e., academic pressure, financial stress, homesickness, 
Journal Committed to Social Change on Race and Ethnicity | Volume 7, Issue 2 | 2021

perceived discrimination, social disconnectedness, and culture shock) and crosscultural adjustment. A systematic review of the literature on psychosocial adjustment of international students between 1990 and 2009 suggested that the most frequently reported predictors of psychosocial adjustment included social support and social interaction with people from the United States (Zhang \& Goodson, 2011).

A systematic review of 18 quantitative studies, published in peer-reviewed journals from 2000 to 2011 on the psychological well-being of East Asian international students, revealed the key variables of these studies as length of stay in the U.S., English proficiency, attitudes towards seeking help, depression, and acculturation (Li et al., 2014). Acculturation difficulties and language difficulties have been shown to impact international students' academic performance (Lowinger et al., 2014). Research has also looked at adaptation difficulty and its impact on emotional well-being in the form of feelings of loss and loneliness (Patron, 2014).

Furthermore, Ee (2013) highlighted the experiences of international students with microaggressions, physical and sexual assaults, race and language related assaults. In a qualitative study utilizing group interviews of six international students focused on issues of international student retention (Bista \& Foster, 2011). Respondents shared that personal safety was among their most important concerns. Research also demonstrates that students from predominantly non-White regions of the world have more negative experiences, which impacts their perceptions and likelihood of recommending international education to other students from their countries (Lee, 2010). Similarly, one of the few studies on international graduate students, researched six females from non-native English speaking countries and found that they experienced 
Journal Committed to Social Change on Race and Ethnicity | Volume 7, Issue 2 | 2021

feelings of discrimination and struggled with acceptance (Contreras-Aguirre \& Gonzalez, 2017). However, overtime international graduate students were able to adapt by building new relationships.

Research suggests that it is possible to facilitate social connection for international students. For instance, Owens and Loomes (2010) conducted a social integration initiative at an Australian university to enhance international students' social adjustment through partnerships with local community, staff, and other students. The initiative included nontraditional U.S. sports (e.g., cricket), as well as social (e.g., celebration of cultural festivals like Chinese New Year and Indian Independence Day), community, communication, work-related, and welfare activities. The researchers also conducted focus-group discussions with staff and students. The findings indicated that successful social integration initiatives were beneficial from both the student and campus staff perspective (Owens \& Loomes, 2010).

Thus, social and emotional safety research indicates that internationals, who are from predominantly non-White or non-English speaking regions of the world, often struggle with adjustment, experience discrimination, macro and microaggressions, and building social connections (Contreras-Aguirre \& Gonzalez, 2017; Ee, 2013; Zhang \& Goodman, 2011). These issues often resulted in feelings of isolation, loneliness, depression (Li et al., 2014; Patron, 2014). However, efforts to integrate them into the local community have been largely successful (Owens \& Loomes, 2010).

\section{Learning Environment and Academic Support}

In addition to physical, sexual, social, and emotional factors, the university or college campus climate or learning environment potentially impacts students' sense of 
Journal Committed to Social Change on Race and Ethnicity | Volume 7, Issue 2 | 2021

safety. Research highlights the vital role played by the campus environment, specifically the sense of community and faculty-student interactions with international students (Glass et al., 2013). Terrazas-Carrillo et al. (2014) conducted semi-structured interviews with seven international students and found that although participants experienced a period of confusion and struggles, they were able to adjust once they made meaningful attachments to the local community. Glass and Westmont-Campbell (2014) found that sense of belonging or community was crucial for academic success. Moreover, international students also identify academic support as a crucial factor in persisting through their U.S. higher education experience (Mamiseishvili, 2012). Despite the recognition of the different challenges of international students, there is a paucity of empirical research on the effect of such experiences on their senses of safety.

\section{Help-Seeking Behaviors}

Research shows that international students are less likely to seek help and use university resources. For example, numerous students reported not using the counseling center on their campus and many others were not even aware of counseling services available to them (Chen et al., 2020). Willis-O'Connor (2014) identified factors that contribute to the underutilization of campus-based counseling services by international students, with culture highlighted as one of the key factors in help-seeking behavior. Mesidor and Sly (2014) reported that $17.7 \%$ of variance in help-seeking intentions for international and African American students was accounted for by socialcognitive factors, such as attitudes, subjective norms, perceived behavioral control, and psychological distress. Shea and Yeh (2008) investigated the impact of adherence to Asian values and the stigma often associated with receiving psychological help by Asian 
Journal Committed to Social Change on Race and Ethnicity | Volume 7, Issue 2 | 2021

American college and graduate students. These investigators found that although female students possessed more positive help seeking attitudes in general, students from Asian countries were unlikely to continue counseling due to the "lack of culturally competent personnel, contradictions between values held by the Asian clients and the Western model of counseling [...] and lack of culturally responsive services" (Shea \& Yeh, 2008, p. 158).

Chen et al. (2020) research explored the influence of attitudes of 113 Chines international students towards seeking mental health based on gender and length of stay. They found that both length of stay and gender did not play a significant role in mental health help-seeking attitudes. However, they found that male students who were unaware of counseling services had a lower attitude towards seeking mental health services than their female counterparts (Chen et al., 2020).

Despite the beneficial implications of such studies, each reported research caveats. For example, generalization was often limited due to sampling and sample size issues. Moreover, instrumentation across current available research on international students' experiences of safety lacked validation and reliability and failed to fully capture psychosocial dimensions. The primary purpose of this study was to develop and validate an instrument to measure the construct of safety among international students in the U.S. and propose ways in which higher education institutions can help increase students' experience of safety on campus.

\section{Research Design and Questions}

The study deployed a cross-sectional psychometric survey design. Along with the human subjects review process, the questionnaire underwent expert review and pilot 
Journal Committed to Social Change on Race and Ethnicity | Volume 7, Issue 2 | 2021

testing prior to administration with an international student sample. Subsequently, to determine the factorial validity and internal consistency of the measure, an exploratory factor analysis (EFA) was conducted. Inherent with EFA, there are no a priori hypotheses, as the researchers are open to the instrument items loading on any of extracted factors. In order words, EFA-derived factors are subjectively labeled based on the underlying content themes represented by the statistical pattern of the item loadings. With psychometric survey studies, therefore, research questions (RQ) are recommended. These research questions were examined: 1) What are the underlying dimensions and internal consistency of the International College Student Safety Questionnaire (ICSSQ)? And, 2) How do international students' experiences of safety in the U.S. differ by demographic? These research questions hypothesizes that international students' experiences of safety as measured by the ICSSQ will differ. The null hypothesis is that international students' experiences will not differ according to the ICSSQ.

\section{Participants and Sampling}

Researchers used convenience and snowball sampling to recruit participants via electronic (international student Facebook groups were messaged, and emails were sent using international student listservs) and in-person surveying (paper copies were distributed at international student events pre-pandemic) methods. As indicated below, investigators also collected participant background data.

\section{Participant Demographic Characteristics}

Demographic items examined respondents' race and ethnicity, nationality, gender expression, college status, current level of adaptation to the U.S. culture, 
Journal Committed to Social Change on Race and Ethnicity | Volume 7, Issue 2 | 2021

perceived proficiency in English, location, and type of institution. Nearly 325 participants from institutions across 30 U.S. states and Washington DC, representing 75 countries from six continents responded. Majority of the participants identified as Asian (60.4\%), followed by Middle Eastern (8.7\%), African (6.5\%), Latine ${ }^{1}$ (4.6\%), which closely coincided with their nationality. Additionally, 15\% identified as White and these included participants from Canada, Europe and Australia. The sample identified as 53\% cismale, $46 \%$ cis-female, while $1 \%$ identified as gender non-binary. Most of the sample were graduate students: $36 \%$ master's and $35 \%$ doctoral, with $23 \%$ undergraduate students. About $3 \%$ reported having not yet adapted to U.S. culture, with $18 \%$ beginning, $55 \%$ having adapted fairly well, and $24 \%$ extremely well. Related to level of English proficiency, 3.5\% reported "low" levels, $34.5 \%$ moderate, and $62 \%$ high.

\section{Instrumentation}

The instrumentation process began with the creation of items using an inductive method (Hinkin et al., 1997). From literature on campus safety and international student experiences, three key dimensions for the initial development phase were identified: (1) physical and sexual safety, (2) social and emotional safety, and (3) learning environment and academic support. Each of these was posited to represent a subscale. An example question for subscale (1) was: "I feel comfortable walking around campus any time of day." An example from subscale (2) was: "When I am struggling with

\footnotetext{
${ }^{1}$ In this paper we used the term Latine to be inclusive of gender non-conforming people. Salinas and Lozano (2021) describe Latine as: "The $\langle-\mathrm{e}\rangle$ suffix replaces the standard $\langle-\mathrm{o} /-\mathrm{a} /-\mathrm{x}\rangle$ ending of nouns and adjectives that are typical of grammatical gender in Spanish. The $\langle-\mathrm{e}\rangle$ is often used as a form of resistance to the $\langle-\mathrm{x}\rangle$, as Latinx has being perceived as another form of systematic oppression in the U.S. to Latin American people. Latine is easier to pronounce in Spanish rather than Latinx" (p. 260).
} 
Journal Committed to Social Change on Race and Ethnicity | Volume 7, Issue 2 | 2021

feelings of homesickness and loneliness, I can usually approach others who will support me." An example from subscale (3) was: "I feel comfortable approaching my professors to ask clarifying questions." Additional items were drawn from other published surveys addressing similar campus safety issues (Wang et al., 2014). A panel of five professional experts, who conduct research on international students, reviewed and revised the items.

The newly developed International College Student Safety Questionnaire (ICSSQ) consisted of 53 indicators. Of these, 41 asked participants to respond on a 7point Likert Scale from 1- Strongly Disagree to 7- Strongly Agree to capture safety perceptions. The remaining 12 items were "Yes/No/Not sure" items examining actual safety experiences of participants.

\section{Data Analysis and Results}

The data set was cleaned, with incomplete and errant entries removed. Thus 284 surveys were usable for statistical analysis, meeting the threshold of less than $5 \%$ missing data. Missing values in remaining cases were replaced with item mean scores as recommended by Graham (2009).

Research Question 1: What are the underlying dimensions and internal consistency (reliability) of the International College Student Safety Questionnaire (ICSSQ)?

The underlying dimensions of the ICSSQ were a four-factor structure: physical and sexual safety, social and emotional safety, campus environment, and campus support. The instrument's internal consistency as measured by Cronbach's alpha was adequate, at .85 . 
Journal Committed to Social Change on Race and Ethnicity | Volume 7, Issue 2 | 2021

The goal for this research question was to ascertain whether the scale measures the construct it intends to measure, and whether it does so consistently, using interpretable subscales to represent the underlying factors of international college student safety. The researchers had initially designed the survey using the three components of physical and sexual safety, social and emotional safety, and learning environment and academic support; but this procedure used participant responses to identify patterns to distinctly cluster the questions into subscales, or factors, representing underlying constructs.

Researchers reviewed parametric properties for each item and removed items 1 , $2,10,12,21,29$, and 30 as they did not meet the assumption of normal distribution required for factor analysis (Kasper \& Unlü, 2013). An analysis of the inter-item Pearson Product correlations demonstrated low-to-high associations among almost all items, ranging from 0.30 to 0.63 . Bartlett's Test of Sphericity, $B(561)=3,310.76, p<0.000$ indicated a favorable correlation matrix and not an identity matrix (determinant $=$ 9.599E-8) indicating multiple constructs could be measured. The Kaiser-Meyer-Olkin Measure of Sampling Adequacy $(\mathrm{KMO}=.807)$ indicated a meritorious value of common variance (Field, 2013).

\section{Prerotation Results}

Initially, both principal component analysis (PCA) and principal (factor) axis analysis (PAF or PFA) were conducted and both found similar variance in the model. Based on the Kaiser (1960) criterion, a total of $58.14 \%$ of the variance was explained by 8 factors with eigenvalues greater than one. Inspection of Cattell's scree test supported four factors, which explained $42.25 \%$ of the variance. 
Journal Committed to Social Change on Race and Ethnicity | Volume 7, Issue 2 | 2021

\section{Rotation}

An oblimin rotation using the four-factor structure resulted in the least evidence of cross-loadings. This allowed the factors to correlate, believing that respondents probably experience campus safety in varied ways simultaneously. A pattern matrix was used to interpret factor loadings due to (a) an increased likelihood for factor stability and (b) the sample was less than ideal for a factor analysis (Comrey \& Lee, 1992). Item communalities were largely within acceptable range (0.3 to 0.8$)$. Eight items, however, failed to load sufficiently on any factor at the minimum level of 0.35 (Comrey \& Lee, 1992; Mvududu \& Sink, 2013). Twenty-six remaining items with loadings between .35 and .85 made up four-factors (see Table 1): campus environment (10 items), social and emotional safety (5 items), physical and sexual safety ( 6 items), and campus support (5 items) accounting for $48.65 \%$ of the total variance. While the instrument was in construction, 3 subscales had been envisioned: physical and sexual safety, social and emotional safety, and learning environment and academic support. Respondents' tendency to answer items on academics and the campus environment differently caused a split in learning environment and academic support to become campus environment and campus support respectively. This latter finding is interpreted in the Discussion. Overall, the 26-item ICSSQ generated a Cronbach alpha of .85. Individual factor alphas ranged from .72 to .81 with no improvement in reliability from further potential item deletions. 
Table 1. International College Student Safety Questionnaire (ICSSQ) PFA Pattern Matrix

\begin{tabular}{|c|c|c|c|c|}
\hline Items & 1 & 2 & 3 & 4 \\
\hline \multicolumn{5}{|l|}{ 1. Campus Environment (10 items) } \\
\hline 19RC: Not treated fairly by American classmates & .71 & & & \\
\hline 7RC: American classmates judged negatively & .69 & & & \\
\hline 35RC: Viewed as less intelligent in the classroom & .65 & & & \\
\hline 13RC: Not treated fairly by university staff & .53 & & & .12 \\
\hline 15RC: Viewed differently due to my appearance, dressing, etc. & .52 & & -.16 & -.11 \\
\hline $\begin{array}{l}\text { 20RC: Struggle forming friendships with people outside of my } \\
\text { culture due to language difficulty }\end{array}$ & .47 & .38 & & \\
\hline 6RC: Heard people on campus make unkind remarks about IS & .46 & & -.22 & \\
\hline 38RC: Fear that reporting a crime might impact visa & .46 & & & .23 \\
\hline 4RC: Sad person & .42 & .17 & & \\
\hline 33RC: Experience academic challenges because of English & .39 & & & \\
\hline \multicolumn{5}{|l|}{ 2. Social and Emotional Safety (5 items) } \\
\hline 16: Make friends easily & & .85 & & \\
\hline 22: Social person & & .67 & & \\
\hline 31: Make friends with American students & & .63 & & .19 \\
\hline 32: Participate in social activities (clubs and/or groups) & -.10 & .52 & & .17 \\
\hline 11: Generally a relaxed person. & & .35 & -.13 & \\
\hline \multicolumn{5}{|l|}{ 3. Physical and Sexual Safety (6 items) } \\
\hline 9: Campus is a safe place & & & -.72 & .19 \\
\hline 8: Comfortable walking around campus any time of day & -.14 & & -.72 & .25 \\
\hline 14RC: Fear of being physically attacked on/around campus & .28 & & -.71 & -.17 \\
\hline 5RC: Fear of being robbed & .16 & .13 & -.58 & -.22 \\
\hline 40: Don't fear walking in the areas outside of campus & & & -.48 & .13 \\
\hline 24RC: Fear of being sexually assaulted on/around campus & .42 & & -.48 & \\
\hline \multicolumn{5}{|l|}{ 4. Campus Support (5 items) } \\
\hline 36: Aware of who to contact for help if a crime on/around campus & .11 & & & .62 \\
\hline $\begin{array}{l}\text { 39: Comfortable using support services when experiencing } \\
\text { difficulty }\end{array}$ & & & .12 & .56 \\
\hline 41: Aware of the student support services on campus & & & & .55 \\
\hline $\begin{array}{l}\text { 37: Aware of what to do to protect myself if a crime on/around } \\
\text { campus }\end{array}$ & & & -.18 & .54 \\
\hline 27: Speak with professors about my challenges & & .12 & & .48 \\
\hline
\end{tabular}


Journal Committed to Social Change on Race and Ethnicity | Volume 7, Issue 2 | 2021

Research Question 2: How do international students' experiences of safety in the United States differ by demographic?

Overall results suggest that an Indian nationality and English proficiency were significant predictors of higher ICSSQ scores overall. Students' statuses (undergraduate, master or doctoral) showed some statistically significant differences as well. Interpretation of the results is found in the discussion section.

In particular, the researchers applied a multivariate analysis of variance (MANOVA) using a general linear model to ascertain what independent variables might explain differences in ICSSQ scores (dependent measures). The demographic variables (gender expression, race and ethnicity, nationality, college status, and perceived proficiency in English) served as independent variables in the model. Across college statuses, the mean (average) score on the ICSSQ was $164.59(S D=22.45)$. A Bonferroni correction was used to limit family-wise error. For ICSSQ total score, a multiple comparisons procedure found that only college status had a significant effect ( $p$ $<.05)$. While not specifically found in previous literature on campus safety for international students, an interesting sub-difference among respondents was found between master's degree students and others. Masters $(M=172.67)$ and doctoral $(M=$ 161.68) students generated significantly higher total ICSSQ scores than first year students (Freshmen: $M=142$ ).

The MANOVA found a statistically significant difference in ICSSQ factor scores and nationality (Wilks' $\lambda=.91, F[8,490]=2.90, p<.004, \mathrm{np}^{2}=.05$ ). Factor 1 (campus environment; $p<.001$ ) and factor 4 (campus support; $p<.01$ ) were the most important subscales in distinguishing nationality. Indian participants scored the highest on all four 
Journal Committed to Social Change on Race and Ethnicity | Volume 7, Issue 2 | 2021

subscales of the ICSSQ. ICSSQ factor scores and college status were also significantly different (Wilks' $\lambda=.86, F[8,508]=5.08, p<.00, n p^{2}=.07$ ) with factors 1 (campus environment; $p<.00$ ) and 3 (physical and sexual safety; $p<.00$ ) distinguishing college status. Master's level students scored the highest on all subscales, except for one while undergraduate students scored slightly higher on factor 2 (social and emotional safety). Finally, perceived proficiency in English (Wilks' $\lambda=.91, F[4,274]=6.40, p<.00, \mathrm{np}^{2}=$ .09) predicted the highest scores on all four subscales of the ICSSQ.

\section{Discussion}

The U.S. higher education system has a vested interest in the welfare of international students (Yao \& Viggiano, 2019). As such, the goal of this study was to gauge international student experiences of U.S. campus, specifically, campus safety given the rise in racial unrest in the American society and many educational institutions. Although, the sample composition was consistent with national statistics on gender expression (Pew Research Center, 2017), it is vital to note that most of the sample consisted of those who were international students pursuing graduate education (master's 36\% and doctoral 35\%), consistent with Pew Research Center statistics (Pew Research Center, 2017). The following discussion first looks at responses from the ICSSQ itself and then the experiential items.

\section{International College Student Safety Questionnaire}

Although a number of studies have identified personal and environmental factors contributing to international students' experiences on college campuses (Babacan et al., 2010; Baba \& Hosoda, 2014; Glass et al., 2013; McLachlan \& Justice, 2009; Zhang \& Goodson, 2011), at the time of writing, the ICSSQ represents the first psychometrically 
Journal Committed to Social Change on Race and Ethnicity | Volume 7, Issue 2 | 2021

sound instrument to assess international students' experiences of campus safety on U.S. higher education institutions. The measure's factorial validity was established as well as its internal consistency. Factors other than physical and sexual safety are needed to understand the construct of campus safety.

The ICSSQ offers four factors: (1) campus environment, (2) social and emotional safety, (3) physical and sexual safety, and (4) campus support (see Table 1). This instrument's factors explained only $48.65 \%$, meaning that experiences of safety are not compartmentalized but are experienced holistically, or from domain to domain. Taken with the adequate Cronbach's alpha for the entire measure, this instrument reinforces a holistic experience of safety due to factor overlap. There was also an unexpected result with the four-factor solution. In conceptualizing campus safety, the instrument was originally constructed with three factors in mind: physical and sexual safety, social and emotional safety, and learning environment and academic support. However, respondents' experiences differed enough within the questions representing learning environment and academic support, as to split that factor into two. They were named campus environment and campus support. This may be done to set apart the importance of having support in an otherwise unsafe-feeling context.

While it predicts students' university experiences, there is a lack of research on international students' experiences. Research on acculturation and cross-cultural adjustment also highlights the importance of environmental factors (Berry, 1997; Heppner et al., 2012). Berry's (1997) model importantly conceptualizes acculturation as a two-way process between international students and their host society, which also reinforces the importance of not leaving the onus of initiating services solely on the 
Journal Committed to Social Change on Race and Ethnicity | Volume 7, Issue 2 | 2021

international student. A concrete example of demonstrating initiatives that are designed to support students comes from Owens and Loomes (2010), as they conducted a social integration initiative to enhance international students' social adjustment through partnerships with local community, staff, and other students. Heppner et al. (2012) highlighted the importance of the level of support or hostility of the environment and relationships within the host culture as factors influencing one's development of crossnational cultural competency. Further research might identify safety as a mediating factor for competency.

\section{Reliability}

As mentioned above, the overall reliability of the ICSSQ was serviceable for an attitudinal measure (Cronbach's alpha $=.85)$. Similarly, the four derived subscales generated satisfactory internal consistency coefficients: campus environment $(\alpha=.80)$, social and emotional safety $(\alpha=.75)$, physical and sexual safety $(\alpha=.81)$, and campus support $(\alpha=.72)$. These reliability estimates for the ICSSQ are congruent to those reported for a relatively similar measure, the International Friendly Campus Scale ([IFCS], Wang et al., 2014) with a composite internal consistency reliability of .89 and subscale score alphas from .70 to .86 .

\section{Experiential Items}

The 12 experiential items on the questionnaire yielded prevalence data on campus safety experiences of international students, which is lacking in the current U.S. literature. In this study, $10 \%$ of the respondents reported experience with theft/robbery on/around campus, similar to the Babacan study (2010), and higher than $0.9 \%$ for fulltime equivalent domestic students (U.S. Department of Education, 2016). In addition, 
Journal Committed to Social Change on Race and Ethnicity | Volume 7, Issue 2 | 2021

$2.5 \%$ reported experiencing physical harm, higher than the $1.4 \%$ found for domestic students (U.S. Department of Education, 2016). Much lower than the $19.6 \%$ reported by (Scholl et al., 2019). Also, about $12 \%$ of the respondents reported experiencing verbal threat/attack, also like Babacan et al. (2010) in Australia.

Unwanted sexual attention can take place in person or over electronic means such as social media. Approximately $7.5 \%$ of the respondents reported experiences with unwanted sexual attention, compared to $13 \%$ reported for all students by the Association of American Universities (AAU; Cantor et al., 2019). However, 7.7\% of the respondents described experiencing unwanted attention or harassment in the form of stalking, which is higher than $5.8 \%$ reported by the AAU Campus Climate Survey (Cantor et al., 2019). In addition, 6\% reported emotional and/or physical abuse, and $4.6 \%$ described receiving unwanted attention or harassment on the internet. However, another study of 829 students did not find higher rates of physical and sexual violence for international students, however, did find differences in rape myths and bystander confidence (Scholl et al., 2019).

Despite relatively high rates of experiences with physical, verbal, and sexual crimes, less than half $(40 \%)$ of the respondents reported utilizing support services on campus. Interestingly, most participants $(82 \%)$ suggested they had spoken to someone regarding their academic needs, but when it came to social-emotional needs and safety, only $14 \%$ and $16 \%$ of the respondents, respectively, sought help. Research endorses these results, as international students are more likely to accept medical issues while finding it much harder to accept emotional issues (Forbes- Mewett \& Sawyer, 2011). 
Journal Committed to Social Change on Race and Ethnicity | Volume 7, Issue 2 | 2021

One of the implications for help-seeking is the need for universities to reach out more actively to offer and destigmatize services to international students.

\section{ICSSQ and Demographic Factors}

While the overall instrument does not differ by demographic variables, such as, gender expression, race, ethnicity, there were some differences on the factors. This result further supports the factor structure, in which international students' status as an international student is likely to result in multiple categories of campus safety or the lack thereof. Here we discuss the demographic differences among participants on the four factors.

Participants who identified India as their country of origin scored higher in comparison to participants from other non-White regions of the world. Existing research suggests that international students from predominantly non-White regions of the world report more negative experiences (Lee, 2010). Negative perceptions tend to decrease the likelihood of international students recommending international education to other students from their home countries. The results of the present study are consistent with the existing literature, in that international students from non-White regions of the world reported lower levels of campus safety on all four subscales, except for international students from India. This anomaly could be explained due to the larger Indian student representation in this sample and due to social desirability bias, which is further explained in the limitations section.

Lastly, most of the participants self-identified their perceived level of proficiency in English as high and scored higher on all four subscales of the ICSSQ. Baba and Hosoda (2014) surveyed 197 international students and found that none of the 
Journal Committed to Social Change on Race and Ethnicity | Volume 7, Issue 2 | 2021

demographic variables, except for comfort levels of communicating in English, were related to cross-cultural adjustment. This variable was positively related to comfort levels of communicating in English $(r=.40, p<.01)$, and negatively related to stress factors, including academic pressure $(r=-.34, p<.01)$, financial stress $(r=-.27, p<$ $.01)$, homesickness $(r=-.44, p<.01)$, perceived discrimination $(r=-.45, p<.01)$, social disconnectedness $(r=-.43, p<.01)$, and culture shock $(r=-.67, p<.01)$. The ICSSQ captured many of the stress factors identified in Baba and Hosoda's study (2014). Therefore, the findings from the current study reinforce those found in previous literature, as those who self-identify as high in perceived English proficiency scored higher on the instrument.

Interestingly, participants who were master's level students scored higher on all subscales except for the social and emotional safety subscale. In contrast, undergraduate respondents indicated a greater sense of social and emotional safety than graduate students. Contreras-Aguirre and Gonzalez (2017) researched female international graduate student and found although they struggled socially and emotionally due to experiences of discrimination, language barriers, and adaption, they are able to gain a sense of personal attainment. This sense of personal attainment and academic success can overshadow the challenges they face, resulting in more positive experiences. However, undergraduate international students experience similar, yet different challenges. For example, Valdez (2015) found that Chinese undergraduate international students struggled with classroom environment and academic support. 
Journal Committed to Social Change on Race and Ethnicity | Volume 7, Issue 2 | 2021

\section{Implications for Practice}

There are several ways the ICSSQ can be used for enhancing international students' experiences on college campuses in the U.S. Assessment results may be deployed to inform strategic planning on which factors of campus safety warrants the most attention for improvement. For example, university sponsored programs and initiatives can be organized that facilitate social connections with U.S. students (Owens \& Loomes, 2010). Universities could pair new international students with other international students from their home countries already established at the university to mentor the newly arrived students (McLachlan \& Justice, 2009).

The most salient recommendation from this research comes from the hesitancy of international students to seek help. Stigma, unwelcoming campus climate, and other alienating factors mean that efforts to breach topics of care relative to international student wellness are needed. Campus services must take a proactive approach rather than waiting for students to approach them. The ICSSQ can be used by college counseling centers to identify which factors impact students' individual experiences on campus. Results from this type of assessment can assist counselors in discussing goals for counseling and support. This can be especially beneficial since the current study and existing literature suggest that there is a lack of willingness among international students in sharing social-emotional needs, due to stigmatization around mental health (Chen et al., 2020; Shea \& Yeh, 2008; Willis-O'Connor, 2014). Such tools can be beneficial in initiating conversations regarding their struggles as an international student. 
Journal Committed to Social Change on Race and Ethnicity | Volume 7, Issue 2 | 2021

College counselors could use opportunities such as orientation (McLachlan \& Justice, 2009) to educate international students about their services and engage in a stronger relationship with incoming international students. Additionally, non-traditional approaches and informal workshops that provide ways for students to obtain skills and learn strategies to adjust within the new culture, manage feelings of loneliness and homesickness, overcome cultural barriers to form friendships within the campus community, and may also assist international students in their transition to the U.S.

The current study highlights certain international students, especially those who identify as students of color, are at-risk of struggling with one or more aspects of campus safety. However, counselors should use caution in generalizing the results from the current study in working with international students. For instance, although Indian international students scored higher on all aspects of campus safety, assumptions that all Indian international students are immune to interpersonal and environmental concerns on campus can be detrimental.

\section{Limitations}

Despite the many advantages of the ICSSQ, there are several limitations. Internal validity is an issue especially important to this study, as it attempted to establish the ICSSQ's psychometric properties with international students. Threats to internal validity in this study most likely included several types of bias, including selection, selfreport, social desirability responding, central tendency, and ordering. Challenges to external validity included convenience sampling and composition of the respondents. Specifically, about one-third of the international students who took this inventory identified as Indian, which is higher than the $18.4 \%$ reported by IIE (2019). Perhaps the 
Journal Committed to Social Change on Race and Ethnicity | Volume 7, Issue 2 | 2021

larger representation of Indian international students is due to the primary researcher's identity as an Indian international student at the time of data collection.

Over $75 \%$ of the respondents were attending higher education institutions in the southern region of the country $(n=245,75.9 \%)$. This study was cross-sectional, so the results of the present study represent a statistical measure of the participants' perceptions and beliefs at the time the participants completed the survey.

In addition to internal and external validity, there were limitations to the data collection procedure. This study was completed using electronic survey methods and inperson paper copies. Although electronic surveys are a common practice (Granello \& Wheaton, 2011), they only allow for data collection over a short period. This study collected data for 8 weeks, which may not have been sufficient to reach the targeted sample. It is impossible to truly know the response rate to this survey as listservs and social media were used to gain access to the sample. Many pertinent listservs and social media groups were restricted to members only, and therefore, the researcher was unable to sample from these groups. Lastly, the item development was mainly based on literature review and input from professionals with expertise in counseling and working with international students. Confirmation bias is possible, due to the expert professionals' theoretical orientations and understandings of international student experience being grounded primarily in the counseling field.

\section{Recommendations for Future Research}

Despite the diversity in the nationality of participants, subsequent investigations of international students' perceptions of campus safety should include more diversity in the various geographical regions within the U.S. (e.g., Northeast, Midwest, and West), 
Journal Committed to Social Change on Race and Ethnicity | Volume 7, Issue 2 | 2021

types of institutions (e.g., private, community colleges) and from more diverse settings (e.g. college towns, rural communities). An overlapping group with relevance to this study are those non-international students of minoritized identities for whom there is ample evidence for experiences of oppression and other aspects of campus safety. The authors suggest that the experiences of students of minoritized identity and international students likely have some overlap. Socio-economic status (SES) was another variable worth considering for future research: while currency and cost of living differences between country-of-origin and the U.S. would likely contribute to international students' socio-economic status, SES may also relate to their experiences of safety in the U.S.

Another key recommendation involves the ICSSQ's validity: a confirmatory factor analysis with a mix of non-international and international students can be conducted with a larger sample to support and refine the measure's dimensionality or construct validity as well as to capture higher explanatory power. In addition, future studies could utilize qualitative methods, such as grounded theory with focus groups to capture the most personal experiences of campus safety among international students, which may have been missed through the broad strokes of a quantitative questionnaire. Longitudinal studies of how perceived campus safety subscales relate to international students' academic retention and completion rates can also provide more information on how campus safety perceptions and experiences impact student success.

\section{Conclusion}

Despite the highly valued contributions of international students on U.S. campuses, there is a major gap in the literature on international students' experiences of campus safety in the U.S. Previous research in this area has emphasized the 
Journal Committed to Social Change on Race and Ethnicity | Volume 7, Issue 2 | 2021

sociocultural challenges that these students experience during their time in western countries like Australia and the U.S. Much discussion has contributed to identifying internal attributes of international students that are related to such experiences, but not enough attention is paid to institutional, structural, and sociocultural contributions to safety and the lack thereof. In an attempt to extend the literature, this study addressed international students' experiences that are embedded in the overall external campus environment, through analyses focused on understanding the construct of campus safety. The current study also examines the impact of demographic characteristics in understanding international students' experiences of safety on campus. From an administrative perspective, both academic professionals, as well as higher education professionals/student affairs personnel, can help facilitate a supportive environment to enhance international students' experiences on campuses in the U.S. The ICSSQ can be applied to varied academic institutions, allowing pertinent staff to obtain a more comprehensive understanding of the campus experiences of international students.

Further, it may validate the experiences of international students which they may not previously have addressed and stir university campuses to action in their responses.

\section{References}

Baba, Y., \& Hosoda, M. (2014). Home away home: Better understanding of the role of social support in predicting cross-cultural adjustment among international students. College Student Journal, 48(1), 1-15.

Babacan, H., Pyke, J., Bhathal, A., Gill, G., Grossman, M., \& Bertone, S. (2010). The community safety of international students in Melbourne: A scoping study. Melbourne: Institute for Community, Ethnicity and Policy Alternatives (ICEPA), Victoria University. http://vuir.vu.edu.au/15491/

Bekmuratova, S. Z. (2012). Study of international students' definitions of, and perceptions about, domestic violence against women. Theses, Dissertations, and Other Capstone Projects. Paper 55. https://cornerstone.lib.mnsu.edu/etds/55

Berry, J. W. (1997). Immigration, acculturation and adaptation. Applied Psychology: An International Review, 46, 5-68. 
Journal Committed to Social Change on Race and Ethnicity | Volume 7, Issue 2 | 2021

Bista, K., \& Foster, C. (2011). Issues of international student retention in American higher education. The International Journal of Research and Review, 7(2), 1-10. https://ssrn.com/abstract=1958362

Cantor, D., Fisher, B, Chibnall, S, Townsend, R., Lee, H., Bruce, C., \& Thomas, G. (2019). Report on the AAU Campus Climate Survey on Sexual Assault and Sexual Misconduct. Association of American Universities. https://www.aau.edu/sites/default/files/AAU-Files/Key-Issues/CampusSafety/Revised\%20Aggregate\%20report\%20\%20and\%20appendices\%2017_(01-16-2020_FINAL).pdf

Chen, H., Akpanudo, U., \& Hasler, E. (2020). How Do Chinese International Students View Seeking Mental Health Services? Journal of International Students, 10(2), 286-305. https://doi.org/10.32674/jis.v10i2.765

Contreras-Aguirre, H. C., \& Gonzalez, E. G. Y. (2017). Experiences of international female students in U.S. graduate programs. College Student Journal, 51(1), 33.

Comrey, A. L., \& Lee, H. B. (1992). A first course in factor analysis. Lawrence Erlbaum. Ee, J. (2013). "Is he an idiot!" Experiences of international students in the United States. Journal of International Students, 3(1), 72-75.

Field, A. (2013). Discovering statistics using SPSS (4th Edition). Sage.

Forbes-Mewett, H., \& McCulloch, J. (2016). International students and gender-based violence. Violence Against Women, 22(3), 344-365. https://doi.org/10.1177/1077801215602344

Forbes-Mewett, H., \& Sawyer, A-M. (2011). Mental health issues amongst international students in Australia: Perspectives from professionals at the coal-face. The Australian Sociological Association Conference Local Lives/Global Networks. University of Newcastle New South Wales.

Glass, C. R., Buus, S., \& Braskamp, L. A. (2013). Uneven experiences: What's missing and what matters for today's international students. Global Perspective Institute. https://www.gpi.hs.iastate.edu/documents/Report-on-International-Students.pdf

Glass, C. R., \& Westmont-Campbell, C. (2014). Comparative effects of belongingness on the academic success and cross-cultural interactions of domestic and international students. International Journal of Intercultural Relations, 38(1), 106119. doi: 10.1016/j.ijintrel.2013.04.004

Graham, J. W. (2009). Missing data analysis: Making it work in the real world. Annual Review of Psychology, 60(1), 549-576.

Granello, D.H., \& Wheaton, J.E. (2011). Online data collection: Strategies for research. Journal of Counseling and Development, 82, 387-393. https://doi.org/10.1002/j.1556-6678.2004.tb00325.x

Hacker, N. L., \& Bellmore, E. N. (2020). "The Trump Effect": How does it impact international student enrollment in U.S. colleges? Journal of Critical Thought and Praxis, 10(1), 1-11. https://doi.org/10.31274/jctp.11588

Heppner, P. P., Wang, K. T., Heppner, M. J., Wang L. (2012). From cultural encapsulation to cultural competence: The cross-national cultural competence model. In Fouad N.A., Carter J. A., Subich L. M. (Eds.), APA handbook of counseling psychology, Vol. 2: Practice, interventions, and applications (pp. 433471). American Psychological Association. 
Journal Committed to Social Change on Race and Ethnicity | Volume 7, Issue 2 | 2021

Hinkin, T. R., Tracey, J. B., \& Enz, C. A. (1997). Scale construction: Developing reliable and valid measurement instruments. Journal of Hospitality \& Tourism Research, 21(1), 100- 120. https://doi.org/10.1177/109634809702100108

Institute of International Education. (2020). United States hosts over 1 million international students for the fifth consecutive year. https://www.iie.org/en/WhyIIE/Announcements/2020/11/2020-Open-Doors-Report

Institute of International Education. (2019). International students in the United States. https://www.iie.org/Research-and-Insights/Open-Doors/Data

Kaiser, H. F. (1960). The application of electronic computers to factor analysis. Educational and Psychological Measurement, 20, 141-151. https://doi.org/10.1177/001316446002000116

Kasper, D., \& Unlü, A. (2013). On the relevance of assumptions associated with classical factor analytic approaches. Frontiers in psychology, 4, 109, 1-20. https://doi.org/10.3389/fpsyg.2013.00109

Lee, J. J. (2010). International students' experiences and attitudes at a US host institution: Self- reports and future recommendations. Journal of Research in International Education, 9(1), 66-84. https://doi.org/10.1177/1475240909356382

Li, J., Wang, Y., Xiao, F. (2014). East Asian International Students and psychological well-being: A systematic review. Journal of International Students, 4(1), 301-313.

Lowinger, R. J., He, Z., Lin, M., \& Chang, M. (2014). The impact of academic selfefficacy, acculturation difficulties, and language abilities on procrastination behavior in Chinese international students. College Student Journal, 48(1), 141152.

McLachlan, D. A., \& Justice, J. (2009). A grounded theory of international student wellbeing. The Journal of Theory Construction and Testing, 13(1), 27-32.

Mamiseishvili, K. (2012). International student persistence in U.S. post-secondary institutions. Higher Education, 64, 1-17. https://doi.org/10.1007/s10734-0119477-0

Marginson, S., C. Nyland, E. Sawir, \& H. Forbes-Mewett (2010). International student security. Cambridge University Press.

Mesidor, J., \& Sly, K. (2014). Mental Health help-seeking intentions among International and African-American college students: An application of the Theory of Planned Behavior. Journal of International Students, 4(2), 137-149.

Mvududu, N. H., \& Sink, C. (2013). Factor analysis in counseling research and practice. Counseling Outcome Research and Evaluation, 4(2), 75-98. https://doi.org/10.1177/2150137813494766

Nyland, C., Forbes-Mewett, H., \& Marginson, S. (2010). The international student safety debate: Moving beyond denial. Higher Education Research and Development, 29 (1), 89- 101. https://doi.org/10.1080/07294360903277364

Owens, A. R., \& Loomes, S. L. (2010). Managing and resourcing a program of social integration initiative for international university students: what are the benefits? Journal of Higher Education Policy and Management, 32(3), 275-290. https://doi.org/10.1080/13600801003743364

Patron, M. (2014). Loss and loneliness among international students. Psychology Journal, 11(1), 24-43. 
Journal Committed to Social Change on Race and Ethnicity | Volume 7, Issue 2 | 2021

Pew Research Center. (2017). Facts on foreign students in the U.S. https://www.pewresearch.org/global/fact-sheet/foreign-students-in-the-u-s/

Postel, E. J. (2020). Violence against international students: A critical gap in the literature. Trauma, Violence \& Abuse, 21 (1), 71-82.

Redden, E. (2020a, July 1). International students' worries during the pandemic. Inside Higher Ed. https://www.insidehighered.com/news/2020/07/01/surveyinternational-students-main-concerns-center-issues-health-safety-and

Redden, E. (2020b, Nov. 16). International student numbers decline. Inside Higher Ed. https://www.insidehighered.com/news/2020/11/16/survey-new-internationalenrollments-drop-43-percent-fall

Renn, K. A., \& Reason, R. D. (2013). College Students in the United States: characteristics, experiences, and outcomes. Jossey-Bass.

Salinas, C. \& Lozano, A. (2021). History and Evolution of the term Latinx. In E. G. Murillo, D. Delgado Bernal, S. Morales, L. Urrieta, E. Ruiz Bybee, J. Sánchez Muñoz, V. B. Saenz, D. Villanueva, M. Machado-Casas, \& K. Espinoza (Eds.), Handbook of Latinos and Education (second edition), (pp. 249-263). Rutledge.

Scholl, J. A., Cogan, C., Micol, R. L., Steward, J., Hancock, K., \& Davis, J. L. (2019). Physical and sexual violence on college campuses: Considerations for international students. Journal of American College Health. doi: 10.1080/07448481.2019.1668398

Shea, M., \& Yeh, C. J. (2008). Asian American students' cultural values, stigma, and relational self-construal: Correlates of attitudes toward professional help seeking. Journal of Mental Health Counseling, 30(2), 157-172. https://doi.org/10.17744/mehc.30.2.g662g5l2r1352198

Terrazas-Carrillo, E. C., Hong, J. Y., \& Pace, T. M. (2014). Adjusting to new places: International student adjustment and place attachment. Journal of College Student Development, 55(7), 693-706.

Urias, D. (2005). Empowering the disenfranchised: Supporting spouses of international students and scholars. International Educator: Foreign Student Affairs, 42-47.

U.S. Department of Education, National Center for Education Statistics. (2016). Indicators of School Crime and Safety: 2015 (NCES 2016-079). https://nces.ed.gov/fastfacts/display. asp?id=804

Valdez, G. (2015). US higher education classroom experiences of undergraduate Chinese international students. Journal of International Students, 5(2), 188-200.

Wang, K. T., Li, F., Wang, Y., Hunt, E. N., Yan, G. C., \& Curry, D. E. (2014). The International Friendly Campus Scale: Development and psychometric evaluation. International Journal of Intercultural Relations, 42, 118-128. https://doi.org/10.1016/j.jijintrel.2014.05.004

Willis-O'Connor, S. (2014). International students' impressions of counseling. Antistasis, $3(1), 11-15$.

Yao, C. W., \& Viggiano, T. (2019). Interest convergence and the commodification of international students and scholars in the United States. Journal Committed to Social Change on Race and Ethnicity, 5(1), 82-109.

Zhang, J., \& Goodson, P. (2011). Acculturation and psychosocial adjustment of Chinese international students: Examining mediation and moderation effects. International Journal of Intercultural Relations, 35, 614-62. 